\title{
Special issue in honor of John C. Rothwell
}

Winston D. Byblow ${ }^{1} \cdot$ Sven Bestmann ${ }^{2}$

Published online: 13 July 2020

(c) Springer-Verlag GmbH Germany, part of Springer Nature 2020

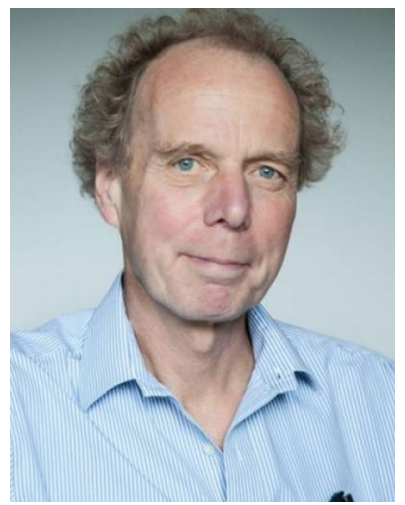

After many years of tremendous service, Professor John Rothwell has stepped away from his editorial post at Experimental Brain Research. In the early 2000s, John served as Managing Editor for a number of years following from Victor Wilson. Then, after working for a period with then Editor-in-Chief, Robert F. Schmidt, John became sole Editor-in-Chief of the journal in January 2009. He served as Editor-in-Chief for a remarkable 11 years until January 2019, when he was joined by Winston Byblow as co-Editorin-Chief. During his tenure as Editor-in-Chief, John oversaw the publication of 4103 articles in the journal. Throughout these years, the journal saw the transition from print to electronic publishing and the rise of Open Access publishing (which is offered by the journal as Open Choice). John was also instrumental in making several key appointments to the Editorial Board, including several of the journal's current section editors. John enjoyed an excellent rapport with his section editors, and this made for open, fruitful, and often amusing annual meetings and dinners near the Springer headquarters in Heidelberg Germany. Before departing, John encouraged the journal to embark upon a "re-fresh" of its

Winston D. Byblow

w.byblow@auckland.ac.nz

University of Auckland, Auckland, New Zealand

2 University College London, London, United Kingdom
Editorial Board to broaden its diversity and expertise across gender, geography and career-stage. As always, John drew from his unique experience as a world-leading scientist in the field of movement control and brain stimulation, while remaining curious about the many topics covered across the various sections of the journal .

John studied physiology in Cambridge, and conducted his PhD studies at King's College, London, under the supervision of David Marsden. He published over 750 articles, and his work has transformed human neurophysiology of healthy and pathological movement. Non-invasive brain stimulation, in particular a technique called transcranial magnetic stimulation, was pioneered by John. Its advent has enabled the non-invasive study of the human corticospinal pathways, during movement planning and execution, and the investigation of cortico-cortical and cortico-spinal changes that occur in the various disorders of human movement control. Before joining the journal as an Editor, John authored several outstanding articles in the journal. Space would never permit full recognition of a complete anthology of his publications, but a few early "classics" published in the journal come to mind. In 1998, with Vincenzo Di Lazzaro and colleagues, he wrote on "Magnetic transcranial stimulation at intensities below active motor threshold activates intracortical inhibitory circuits" (Exp Brain Res 119, 265-8), an article which has amassed an impressive 397 citations, and provided a framework for hundreds of subsequent studies examining inhibitory circuits in motor cortex and their relevance for motor control. In the same year, he co-authored "Facilitation of muscle evoked responses after repetitive cortical stimulation in man" (Exp Brain Res 122, 79-84) which to date, has also been cited over 300 times, and again provided foundational insight into motor cortex function. In addition, in 2003, along with Hartwig Siebner, they wrote "Transcranial magnetic stimulation: new insights into representational cortical plasticity" (Exp Brain Res 148, 1-16), an article which to date has been cited a remarkable 487 times, and has informed countless studies, and helped new protocols, for examining motor cortex plasticity. John's remarkable ability to apply the techniques he developed to the study of 
disorders of movement has given us major insights into the pathophysiology of dystonia and different forms of myoclonus, the mechanisms of action of deep brain stimulation for the treatment of movement disorders, such as Parkinson's Disease, the neurophysiology underlying post-stroke reorganisation, and several others. Many of these topics are featured in this Special Issue.

To celebrate John's tenure as Editor-in-Chief of Experimental Brain Research, we have compiled this Special Issue to coincide with John's retirement from University College London, where he worked at the Institute of Neurology for the majority of his career. Sadly, due to the global outbreak of Covid-19, a special symposium to mark John's retirement was cancelled at the last minute. We hope that in some small way, this Special Issue can fill some of the void left by the hundreds who could not gather in person to honour John at the planned event. The Special Issue in honour of John Rothwell contains articles written by a vast array of John's international friends, collaborators, and former students as well as some tributes from former colleagues-many of whom have spent time in John's lab at one stage in their career. Not only do these contributions pay tribute to John, but they also discuss some very important issues of the present day related to the control of human movement. Of the handful of original articles in this issue, it is clear that many were influenced directly by John's pioneering studies on magnetic stimulation, like those mentioned above.

It is worth noting from the outset that there were many more requests to contribute to the Special Issue than we could possibly accommodate. The response to the Call for the Special Issue was overwhelming, which signifies the high regard for John from international colleagues, former collaborators, and those 'at arm's length' who wanted to express how much John's research has shaped their own. We are delighted that the Special Issue contains a broad mix of insightful and topical reviews, original research articles, and commentaries that without exception draw upon John's past and recent contributions to human neurophysiology and motor control.

Publisher's Note Springer Nature remains neutral with regard to jurisdictional claims in published maps and institutional affiliations. 